\title{
BMJ Open Rethinking pain education from the perspectives of people experiencing pain: a meta-ethnography to inform physiotherapy training
}

Kate Thompson (D) , ${ }^{1,2}$ Mark I Johnson (1) , ${ }^{1,2}$ James Milligan, ${ }^{1,2}$ Michelle Briggs ${ }^{3}$

To cite: Thompson $\mathrm{K}$, Johnson MI, Milligan J, et al. Rethinking pain education from the perspectives of people experiencing pain: a meta-ethnography to inform physiotherapy training. BMJ Open 2022;12:e046363. doi:10.1136/ bmjopen-2020-046363

- Prepublication history and additional supplemental material for this paper are available online. To view these files, please visit the journal online (http://dx.doi.org/10.1136/ bmjopen-2020-046363)

Received 03 November 2020 Accepted 11 November 2021

Check for updates

(c) Author(s) (or their employer(s)) 2022. Re-use permitted under CC BY-NC. No commercial re-use. See rights and permissions. Published by BMJ.

${ }^{1}$ School of Health, Leeds Beckett University, Leeds, UK

${ }^{2}$ Centre for Pain Research, Leeds Beckett University, Leeds, UK

${ }^{3}$ Division of Nursing, Midwifery \& Social Work, Manchester University NHS Foundation Trust, Manchester, UK

\section{Correspondence to}

Kate Thompson;

k.a.thompson@leedsbeckett. ac.uk

\section{ABSTRACT}

Background Pain is a complex, global and multidimensional phenomena that impacts the lives of millions of people. Chronic pain (lasting more than 3 months) is particularly burdensome for individuals, health and social care systems. Physiotherapists have a fundamental role in supporting people who are experiencing pain. However, the appropriateness of pain education in pre-registration physiotherapy training programmes has been questioned.

Recent research reports identify the need to integrate the voice of patients to inform the development of the preregistration curriculum. The aim of this meta-ethnography was to develop new conceptual understanding of patients' needs when accessing physiotherapy for pain management. The concepts were viewed through an educational lens to create a patient needs-based model to inform physiotherapy training.

Methods Noblit and Hare's seven-stage metaethnography was used to conduct this qualitative systematic review. Five databases (MEDLINE, CINAHL Complete, ERIC, PsycINFO and AMED) were searched with eligibility criteria: qualitative methodology, reports patient experience of physiotherapy, adult participants with musculoskeletal pain, reported in English. Databases were searched to January 2018. Emerge reporting guidelines guided the preparation of this manuscript.

Results A total of 366 citations were screened, 43 full texts retrieved and 18 studies included in the final synthesis. Interpretive qualitative synthesis resulted in six distinct categories that represent patients' needs when in pain. Analysing categories through an education lens resulted in three overall lines of argument to inform physiotherapy training. The categories and lines of argument are represented in a 'needs-based' model to inform pre-registration physiotherapy training. Discussion The findings provide new and novel interpretations of qualitative data in an area of research that lacks patient input. This is a valuable addition to pain education research. Findings support the work of others relative to patient centredness in physiotherapy.

\section{INTRODUCTION}

Pain has a substantial impact on health and social care systems globally, with over 28 million people in the UK experiencing
Strengths and limitations of this study

- Meta-ethnography is well aligned to this area of research as it is particularly suitable for developing conceptual understanding or developing conceptual models.

- Meta-ethnography is suited to analytical rather than descriptive evaluation of qualitative data allowing data to be viewed through an education lens.

- Eligibility criteria was purposely broad therefore the studies in the meta-ethnography include participants with diverse painful musculoskeletal conditions.

- Meta-ethnography only includes qualitative studies though these can include different study designs, therefore, the studies in this meta-ethnography were diverse.

- Study participants were not directly asked for their views on pain education. Existing qualitative data was reinterpreted through an education lens.

chronic pain. ${ }^{1-6}$ Supporting people in pain is complex because pain is multi-dimensional with biomedical, psychological and social components. $^{7}$ Chronic pain (greater than 3 months duration) can be particularly challenging when characterised by significant emotional distress or functional disability. ${ }^{8}$

Supporting people in pain is fundamental to the physiotherapy role. Physiotherapists working in outpatient settings support patients with a broad range of painful musculoskeletal conditions. In 2019, the World Confederation of Physical Therapy dedicated its World Physical Therapy Day to chronic pain to raise awareness about the crucial role the profession plays in pain management. It is essential that physiotherapists are trained with the knowledge and skills to be able to support people who are experiencing pain, particularly those with complex chronic pain.

What is pain education?

Previously, we conducted a scoping review to identify research and policy relevant to 
pre-registration pain education across multiple health professions. The review was purposely broad to benchmark physiotherapy to other health professional training (eg, nursing, medicine and other allied health professions).$^{9}$ Pain education was found to be predominantly theoretical where students learn about current understanding of pain science. Pain education research was commonly found to be surveys, that gathered information about the coverage of pain knowledge in the curriculum. There was very little research including patients' views about pain education in preregistration training. This is significant because arguably people living with pain are the best educators of what pain is and are best placed to provide experience and context for pain education. ${ }^{10} 11$

Our research team consists of clinicians, academics and researchers. We believe there needs to be a shift towards more practical focused pain education whereby pain management skills and person-centredeness are developed through training and are underpinned by contemporary pain science. To make this shift, there is a need to integrate the voice of patients into physiotherapy education and training about pain. This corroborates research findings that physiotherapists do not always feel skilled and confident in pain management skills. ${ }^{12-16}$

\section{Patients perspectives in other areas of pain research}

Patient advocates have advised that students should focus on the impact of pain, and listen to and believe patients' stories. ${ }^{10}$ The importance of communication skills and empathy are highlighted. ${ }^{10}$ Health professionals are asked to reflect on their own attitudes about pain and how this might impact their clinical practice. ${ }^{10}$ Patients have been asked for their views regarding gaps in pain management knowledge for medical students (explored by focus groups of patients, students and educators). ${ }^{11}$ Five themes were reported to inform medical education: educational approaches need to teach students to gather appropriate information about pain, to acquire knowledge of a broad spectrum of therapeutic options, to develop a mutual, trusting relationship with patients and to become aware of their own biases and prejudice towards patients with pain. ${ }^{11}$ These findings are applicable to preregistration medical training though indicate important areas of consideration for preregistration physiotherapy training.

Qualitative research exploring the views of patients has provided important insights for the development of therapeutic pain education. These include concepts to enhance pain neuroscience education (PNE), ${ }^{17}$ the relevance of PNE to patients, ${ }^{18}$ barriers to chronic pain management, ${ }^{19}$ and the impact of PNE on living with pain. ${ }^{20}$ Qualitative methods have been used to fill gaps in pain understanding by descriptive or interpretive approaches that other research methodologies cannot. ${ }^{21}$

\section{Qualitative evidence synthesis}

Preliminary searches of databases revealed several qualitative studies that have explored patient experience of physiotherapy for musculoskeletal pain. Collectively, these studies provide broad insight into patient experience of physiotherapy across a range of musculoskeletal settings. Synthesising the findings from these qualitative studies of patient experience can provide new conceptual understanding of patients' needs. Viewed through an education lens, patient experience can inform pain education in physiotherapy training.

Qualitative synthesis is useful in education research to provide in-depth information, understanding and context to inform educational decision making. ${ }^{22}$ This is a valuable addition to pain education research where quantitative research currently dominates. ${ }^{23}$ Several methodologies are able to synthesise qualitative research. ${ }^{24-26}$ Noblit and Hare's work was originally rooted in the field of education. ${ }^{27}{ }^{28}$ It has been successfully used to synthesise and reinterpret qualitative research data to understand the experiences of patients living with chronic pain ${ }^{29}$ and to understand the experiences of healthcare professionals treating adults with chronic pain. ${ }^{30}$ Meta-ethnography was therefore chosen to synthesise qualitative data in this study. Guidelines for reporting meta-ethnography have been used to conduct the research and prepare this manuscript. ${ }^{31}$

\section{Aim}

To develop concepts that help understand patients' needs when accessing physiotherapy because they are experiencing musculoskeletal pain, to inform pain education in pre-registration training.

\section{Objectives}

1. To develop conceptually rich insight into patients' needs and experiences when accessing physiotherapy because they were experiencing musculoskeletal pain.

2. To interpret, synthesise and translate findings into conceptual categories that reflect patients' needs and experiences.

3. To view these categories through an educational lens, developing lines of argument to inform pain education in preregistration physiotherapy training.

\section{METHODS}

The seven stages of meta-ethnography originally described by Noblit and Hare were used to structure the methodology for the study. ${ }^{28}$

\section{Phase 1: getting started}

Preliminary searches were conducted in several health databases (up to January 2018) to identify studies that explored patients' experience of physiotherapy for musculoskeletal pain. One author (KT) developed and piloted the search strategy that all review team members evaluated and refined (online supplemental file 1). Boolean operators combined key search words [patient OR service user OR client] AND [experience OR perspective OR view OR perception OR attitude] AND [qualitative OR focus group OR interview] AND [physiotherapy OR 
physical therapy] AND [pain] in the following databases: MEDLINE, CINAHL complete, ERIC, PsycINFO and AMED. Reference lists of key papers were subsequently searched. One author (KT) and a research intern (Steven Williams) independently screened titles and abstracts using the following eligibility criteria:

1. Adult participants with musculoskeletal pain (acute or chronic).

2. Qualitative methods.

3. Findings report patient experience of physiotherapy

4. Abstract and full text reported in English.

Eligibility criteria were purposely broad to gain concepts from diverse patient experience of musculoskeletal physiotherapy. This was to reflect routine clinical practice in musculoskeletal outpatient physiotherapy. To provide transparency in data analysis, data extraction tracked and logged the studies that concepts evolved from. This information is reported as part of the results.

\section{Phase 2: deciding what is relevant}

Research studies were excluded if they reported experiences of physiotherapy for non-musculoskeletal pain that would not typically be managed in musculoskeletal outpatient physiotherapy settings. Examples include cancer pain, cardiac pain and postsurgical pain. Research studies that discussed physiotherapy as part of multidisciplinary chronic pain rehabilitation were included if data could be extracted that clearly reflected physiotherapy. A third member of the team (MB) acted as arbiter for any disagreements. The full team met to review and check eligibility decisions agreeing that 18 papers were eligible

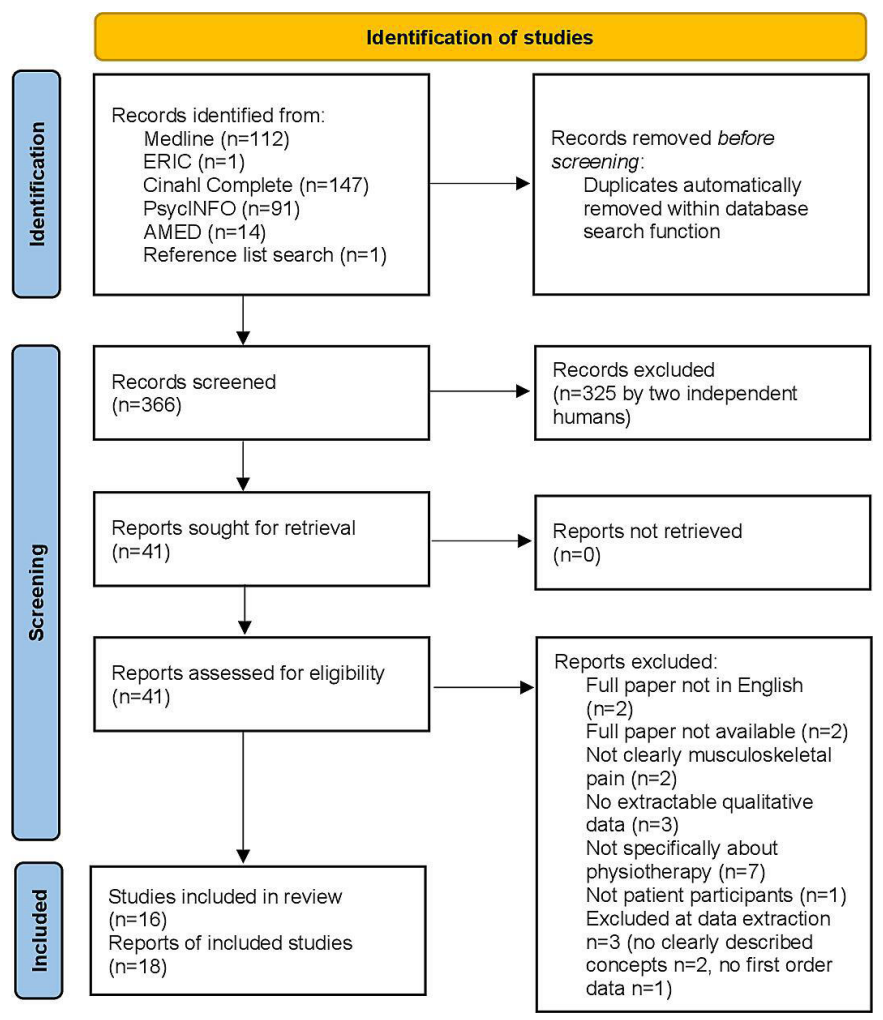

Figure 1 Results of searching and screening. for the next stage of the review (online supplemental file 2). Figure 1 presents the searching and screening results.

\section{Phase 3: reading the studies}

One author (KT) used the Critical Appraisal Skills Programme (CASP) tool ${ }^{32}$ to facilitate thorough reading, to make notes for discussion with the review team, and to note bibliometrics from each study. Quality appraisal using CASP did not score papers for eligibility for inclusion in the review.

\section{Phase 4: determining how studies are related}

Data were extracted from studies using NVivo qualitative management software ${ }^{33}$ and Schutz's concept of first and second order constructs. ${ }^{34}$ Second order constructs are concepts, themes and rich descriptive data clearly described by the authors of the studies included in the review. First order constructs are research participants' quotations. ${ }^{35}$ Second order constructs were only extracted if they were supported with first order constructs. Contextual data about each study (bibliometrics, purpose, context, meaning) was logged using memos.

One author (KT) extracted all second order constructs (along with their respective first order constructs) using NVivo. These were exported to Word documents where they were discussed by the team and grouped thematically according to interpreted meaning.

\section{Phase 5: translating studies into one another}

The thematic groups identified in phase four were further analysed. Second order constructs with common and mutual findings were identified and recorded as reciprocal synthesis. Second order constructs with opposing or contradictory findings were identified and recorded as refutational synthesis. ${ }^{28}{ }^{35}$ In meta-ethnography methodology this is 'translating studies into one another'.

This was an iterative process. Second order constructs moved between thematic groupings until the review team agreed. At the end of stage five, the thematic groups became distinct categories. (Online supplemental file 3 provides a brief extract demonstrating analysis notes on reciprocal and refutational synthesis.

\section{Phase 6: synthesising translations}

In phase six, a narrative for each of the categories agreed in phase five was written. One author (KT) drafted the first narrative for each category. All review members debated and refined the narrative until we agreed that the narrative accurately reflected the essence of the second order constructs within that category. Categories were viewed through an educational lens to interpret lines of argument for pain education.

\section{Phase 7: expressing the synthesis}

The findings from this meta-ethnography are intended to inform pain education for pre-registration physiotherapy training. Findings may be of interest to the wider multidisciplinary team and patients. 


\section{Patient and public involvement}

The review team conducted two focus groups with patients who had accessed physiotherapy for pain management, to gather their views and steer the direction of our portfolio of pain education research. This meta-ethnography was included in these focus group discussions.

\section{RESULTS/FINDINGS}

\section{Phase 1-3}

The results of searching and screening are presented in figure 1. Eighteen studies were eligible for data extraction and analysis (online supplemental file 2) ${ }^{36-53}$ One author (KT) used the CASP tool ${ }^{32}$ to facilitate discussion of the study methodologies with the review team, and to note bibliometrics from each study. Quality appraisal using CASP did not score papers for eligibility for inclusion in the review.

Study samples comprised participants experiencing predominantly chronic pain ( $\mathrm{n}=11$ studies), acute pain ( $\mathrm{n}=1$ studies) or mixed samples ( $\mathrm{n}=6$ studies). Participant data were collected by interviews ( $n=13$ studies), focus groups ( $\mathrm{n}=4$ studies) and by open text comments on survey $(n=1$ study). Some study reports stated the aetiology, pathophysiology, clinical diagnosis or predominant site of pain though the quality and detail of information varied between reports. Physiotherapy settings included outpatients $(n=13)$, group physiotherapy $(n=3)$, multimodal/ multiprofessional pain management $(n=3)$ and residential multidisciplinary pain management $(n=1)$. Second order constructs collectively represented more than 300 study participants (from those conducting interviews and focus groups) and 1259 qualitative comments (from the open text survey questionnaire). The participants in the studies included in this review represent diverse and broad experience of physiotherapy for musculoskeletal pain. All participants were accessing physiotherapy because they had musculoskeletal pain. Online supplemental file 4 has been included to provide transparency in analysing data from diverse studies. Online supplemental file 4 provides information to demonstrate which studies support each of the categories outlined in phase 5 .

\section{Phase 4}

Second order constructs were provisionally grouped into twelve 'themes' and 'labelled' according to shared interpreted meaning:

1. An acceptable explanation for pain.

2. Professional influence/seeking hope and direction from physiotherapy.

3. Perceptions of effectiveness/speed of improvement.

4. Supported self-care/shared decision making/respect and dignity.

5. Complex emotions accompany chronic pain/supportive environment.

6. The health service 'merry-go-round', that is, continuous cycle of consultations repeating story.
7. Exercise-a strategy and barrier for patients who are in pain.

8. Embedded/embodied experience of pain.

9. Sharing experiences, benchmarking, validation, perceptions of effectiveness.

10. Creating new patterns of thinking and acting, behaviour change, transition in healthcare.

11. Motivating factors-intrinsic and extrinsic motivations, incentives, technology.

12. How/who makes decisions.

\section{Phase 5}

The initial groups described in phase four evolved to become six distinct categories. Each category, listed below, was interpreted to encapsulate a distinct element of patients' needs when accessing physiotherapy with musculoskeletal pain. An example of data analysis is provided in online supplemental file 3. Information to demonstrate and provide transparency in which studies support each category is provided in online supplemental file 4.

1. People in pain are individuals.

2. What does pain mean?

3. Pain is complex-there is a lot to learn.

4. Pain management needs to be accessible and realistic.

5. Hope is really important - the power of health professionals.

6. Context matters.

\section{Phase 6}

In this section a brief narrative of the six categories is presented along with a selection of second order constructs as exemplars.

\section{Category 1: people in pain are individuals}

This category includes second order constructs extracted from 8/18 included studies. Participants were predominantly experiencing chronic low back pain (CLBP), neck pain, fibromyalgia and chronic widespread pain (online supplemental file 4). Synthesising the concepts from these studies revealed that participants want to be listened to, believed and enabled to actively participate in a two-way consultation. This included respecting individual beliefs, values, thoughts, opinions and previous experiences. Participants need an environment that enables individual perspectives and experiences to be discussed and explored. Participants frequently reported the importance of a professional yet personal manner, including friendliness and empathy. Some participants wanted their treatment to be decided and prescribed by the physiotherapist because they viewed the physiotherapist as the expert. Other participants described the benefits of a more consultative approach and joint decision making. This category highlights the importance of treating people as individuals, and consulting patients about their beliefs and preferences when undertaking physiotherapy pain assessment and pain management. 
Second-order construct: Cooper et al - Individual care

Communication played a role in participants perceiving that treatment was individualised to their needs. Listening, understanding and getting to know the patient, and allowing the patient to explain their problem and to question the physiotherapist were recurrently cited in relation to this dimension. ${ }^{37}$

\section{Second-order construct: May - Consultative process}

The third dimension of physiotherapy care that is mentioned widely concerns treatment which is seen to involve a level of consultation with the patient. This relates to some of the themes mentioned earlier, but nonetheless features frequently enough to stand as important in its own right. It includes such issues as listening and responding to patients' questions, consulting with them about the effectiveness of therapy, and relating treatment to their individual self-help needs. ${ }^{44}$

\section{Second-order construct: Cooper et al - Decision making}

Most participants expressed the view that since the physiotherapist is the professional or expert, they should decide what is best for the patient. However, this was very much linked with communication, since participants were happy for the physiotherapist to make most decisions as long as they were accompanied by good explanations. ${ }^{37}$

\section{Second-order construct: Stenberg et al - To be invited to participate}

The patients felt that they had been invited to participate in the assessment and treatment options if their own theories about the condition were listened to and confirmed. When their own thoughts about the causes of the pain were ignored or rejected, or when they were not invited to take part in the treatment, they were frustrated even if they had become pain-free. ${ }^{48}$

\section{Category 2: what does pain mean?}

This category includes second order constructs extracted from 7/18 included studies (online supplemental file 4 ). The experiences of people with chronic pain have more substantive coverage though constructs evolved from studies including participants with pain of mixed duration. Synthesising the concepts from these studies revealed that information is critical to help people understand and navigate the complex nature and meaning of pain. However, 'one-size' does not fit all-finding acceptable explanations for what pain means to individuals is dependent on individuals' beliefs and previous experiences, highlighted by the previous category in this metaethnography. Participants who had found an acceptable explanation for their pain described it as empowering, a tool for self-management, and enhanced adherence and compliance with physiotherapy. The findings in this category demonstrate the crucial role that physiotherapists have in facilitating conversation about pain; to analyse patient narrative to understand what explanatory model is being used by the patient to underpin the meaning of their pain.
Second-order construct: May - Explaining and teaching

A major segment of the data was about the physiotherapists' role in explaining and teaching, which was a characteristic of an episode of care deemed important by nearly all respondents. This should not be seen as a straightforward transmission of knowledge to passive recipients, but an active process in which the patients gain a greater understanding of their condition, and as a consequence manage it better. ${ }^{44}$

Second-order construct: Campbell et al - Ideas about the cause of arthritis

Ideas about the cause of arthritis also played a part. Those who thought that arthritis was caused by immutable factors such as age, obesity and 'wear and tear', tended to have a resigned attitude towards their arthritis. As a consequence they found it hard to believe that the intervention could be effective and this weakened the resolve to comply. ${ }^{36}$

\section{Second-order construct: Cooper et al - Information sharing}

Participants commonly wanted information related to their diagnosis and what it meant for them... of course, physiotherapists may not always be able to fulfil these needs, particularly where there is no specific diagnosis. However, these results do suggest that the type of information that patients are searching for should at least be explored, and the physiotherapist should explain what information they can confidently provide. ${ }^{37}$

\section{Category 3: pain is complex: there is a lot to learn}

This category includes second order constructs extracted from 10/18 included studies (online supplemental file 4). Study participants presented with acute and chronic pain. This category describes patients' needs in learning to understand, appreciate and navigate the mind-body link when experiencing pain. There is some overlap with the concepts in category 2, however, the high frequency of reciprocal findings across studies resulted in a distinct category. Physiotherapeutic approaches that made participants more aware of the impact of thoughts and emotions on pain, activity levels and behaviour were interpreted to be positive. Approaches that facilitate validation and understanding of the mind-body relationship were described to be instrumental in moving forward when experiencing pain. The concepts in this category demonstrate the importance of training physiotherapist with the skills to be able to help people navigate the complex mind-body link.

Second-order construct: Toye and Barker - Bringing my body back into balance

Central to this concept was that patients who had improved significantly had accepted that there was a link between the mind and body, without allowing this to challenge their legitimacy. Some even said that their problem was 'more mental than physical'. 
Second-order construct: Liddle et al - Effects of LBP on the individual

In particular, during the initial stages of LBP, participants lacked confidence, and felt that they had no control over their symptoms. They also worried about the possibility of there being permanent damage to the spine, which precipitated a mixture of emotions, the most common being fear, anger, depression and guilt. Participants also discussed how LBP had inhibited them on a physical and emotional level, and how their daily lives had changed as a result of their condition. ${ }^{41}$

\section{Second-order construct: Mårtensson and Dahlin-Ivanoff -}

\section{Awareness and integration}

This theme describes how the content of programme made the participants aware of their physical and psychological limitations as well as of their own responsibility to pay attention to and respect these. It also describes experiences of integrated and applied knowledge acquired from the practical and theoretical parts of the course. ${ }^{43}$

\section{Category 4: pain management needs to be accessible and realistic}

This category includes second order constructs extracted from 10/18 included studies (online supplemental file $4)$. Synthesising second order constructs in this category revealed that many patients need physiotherapy to be pragmatic and accessible and considerate of personal circumstances. Findings across studies were mostly reciprocal with participants frequently expressing similar views about the accessibility of, choice and range of options when accessing healthcare when experiencing pain. Challenges adhering to physiotherapy included managing time, relationships and work alongside physiotherapy treatments. Healthcare systems were not always described as fit for purpose for example, 'one-size' approaches such as exercise classes did not always feel individualised to participants' needs. People living with chronic pain described needing a healthcare system that was accessible like other long-term conditions. They wanted access without renegotiating the healthcare system each and every time. This category highlights physiotherapists' role in challenging the structure and organisation of existing services that may not be fit for purpose for people with complex chronic pain.

\section{Second-order construct: Cooper et al - Organisation}

Access to physiotherapy and the amount received were important organisational aspects for these participants. Access in the future was a common theme, with participants wanting quick and direct access in the event of a flareup. ${ }^{37}$

Second-order construct: May - The structure that shaped access to and time with the therapist

Issues about the structure of provision of physiotherapy care were raised frequently. Patients appreciated quick and local access to a therapist when this occurred, and were equally critical of a protracted referral system when this was the case. Quite a number of respondents talked about the usefulness of being able to return to the therapist should the need arise, for instance during a flare-up of their problem. ${ }^{44}$

Second-order construct: Mårtensson and Dahlin-Ivanoff - Reacting but not acting

This theme describes experiences in which dissatisfaction with the content and format of the programme was expressed. This frustration was never vented during the course because the content was described as taken for granted and it was presumed that the format was predetermined and could not be influenced. ${ }^{43}$

Second-order construct: Cooper et al - Self-managing, want future access

This largest group of participants described themselves as self-managing, and discussed self-management strategies they used to cope with their CLBP. There were both painful and pain-free participants in this group. All wanted direct access to physiotherapy and/or follow-up in the future. ${ }^{38}$

\section{Category 5: hope is important: the power of health professionals}

This category includes the most substantive coverage with second order constructs from 14/18 studies contributing (online supplemental file 4). Synthesising second-order constructs in this category revealed the importance of 'hope' as a concept. Participants in the included studies frequently voiced needing hope when seeking help from physiotherapists. Reciprocal synthesis repeatedly demonstrated the uncertainty and lack of confidence that participants were experiencing due to pain. They sought hope, reassurance and guidance from the professional person. Some findings were interpreted to be refutational for example, passive versus active responsibility and confidence in own ability to manage pain. The patient-therapist relationship features within this category with reciprocal findings that physiotherapists can influence beliefs and behaviours. Physiotherapists' role in coaching and motivating others, and fostering self-efficacy in people experiencing pain, evolved as an important concept from this category.

Second-order construct: Toye and Barker - Hopes for the future An overarching theme that subsumed these narratives of success was a restored hope for the future. Patients described this as 'like a light being switched on'. Restoration of hope hinged on three narratives; (1) deconstructing fear of specific movements, (2) constructing an acceptable explanatory model of pain and (3) reconstructing an acceptable self-identity. ${ }^{50}$

Second-order construct: Liddle et al - Expectations from treatment The need for individually specific exercises and advice regarding suitable lifestyle adaptations became increasingly more important as individuals took more responsibility for their recovery. Supervision of exercise 
programmes was considered important in order to provide individual correction: participants expressed the need for follow-up support and reassurance from the practitioner that they were carrying out instructions correctly, and assistance with appropriate treatment progression in line with their stage of recovery. ${ }^{41}$

\section{Second-order construct: Williamson et al - Where do beliefs come} from? health professionals

Health professionals exerted substantial influence over how participants thought about or managed their injury and the expectation of time taken to recover. ${ }^{52}$

\section{Category 6: context matters}

This category includes second order constructs extracted from 8/18 included studies (online supplemental file 4). This category represents participants' views and opinions about physical, social environments and relationships. Patients access physiotherapy with different experiences, and experience physiotherapy differently. Synthesis of second order constructs revealed that participants reflected on environments that are structured and organised by healthcare providers, and those that participants encountered as part of everyday life. Healthcare environments that promoted feelings of relaxation, a sense of belonging, and a safe environment to express thoughts and emotions were reported to be encouraging and motivating. Physical surroundings (such as exercise equipment and technology) featured within this category with technology generally perceived to be positive within physiotherapy pain management. This category emphasises the physiotherapists' role in considering individuals' contexts, creating supportive and encouraging environments, and in supporting people to recognise the impact of personal environments, within the boundary of their professional role.

\section{Second-order construct: Mårtensson and Dahlin-Ivanoffan - Encouraging environment}

This theme describes the participants' experiences of the format and design of the programme as an encouraging environment in which their own needs, thoughts and opinions were appreciated and respected. ${ }^{43}$

\section{Second-order construct: Medina-Mirapiex et al - Perceptions of physical environment}

Patients report having effective resources from the physical environment to overcome perceived barriers. These resources include using entertainment, such as television at home, and attendance at recreational centres. Some patients even feel that attending recreational centres is fundamental for adherence in post-treatment periods. ${ }^{45}$

\section{Second-order construct: Mannerkorpi and Gard - Sharing}

experiences of living with fibromyalgia

Participation in the group treatment appeared to involve frequent social interaction, leading to repeated confrontations with one's own and others' life-worlds. Three patterns of participation were identified: 'reciprocity in

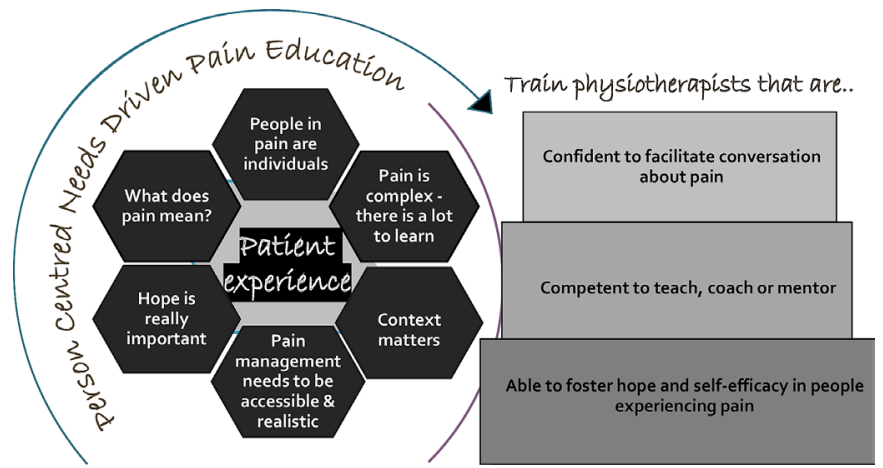

Figure 2 A patient needs-based approach to inform pain education in preregistration physiotherapy training.

sharing experiences', 'distancing from others' experiences' and 'remaining outside'. ${ }^{42}$

Second-order construct: Williamson et al - Beliefs: fitting it all in Competing priorities impacted on how individuals managed their injury. Family commitments made it difficult to prioritise time to concentrate on their recovery or even attend appointments for some participants. ${ }^{52}$

The review team met several times to discuss how these categories inform pain education. We had open debate and reflected on the categories in relation to our own experiences as clinicians, researchers, academics and educators. We agreed that the categories encapsulate the importance of interpersonal skills, the power that health professionals hold when viewed as experts, and that people experiencing pain are individuals irrespective of the duration of pain. Our analysis led us to three overall lines of argument to inform pain education in preregistration physiotherapy training:

1. Train physiotherapists to encourage and facilitate conversation about pain.

2. Train physiotherapists to be competent to teach or coach people who are experiencing pain.

3. Train physiotherapists to foster hope and self-efficacy in people who are experiencing pain.

The categories and lines of argument are represented visually to create a patient needs-based model to inform preregistration pain education (figure 2). The next section of this manuscript discusses these lines of argument relative to other literature in the field.

\section{DISCUSSION}

The findings from this meta-ethnography reveal important concepts to inform pain education in preregistration physiotherapy training, interpreted from patient experience. This is a valuable addition to pain education research, providing new and novel interpretations of qualitative data in an area of research that lacks patient input.

Line of argument 1: train physiotherapists to encourage and facilitate conversation about pain

The categories in this meta-ethnography demonstrate the importance of understanding patients' individual 
context when they are experiencing pain. Incorporating listening and communication skills as part of a biopsychosocial approach in preregistration training is essential for this, and already advocated as part of pain education and pain management by pain organisations globally. ${ }^{54-57} \mathrm{We}$ advocate that, in addition to the development of active listening and communication skills, more focus is placed on narrative, dialogue and language in preregistration physiotherapy training. Learning to facilitate conversation about pain allows physiotherapists to understand what explanatory model patients are using to underpin the meaning of their pain; to interpret narrative that patients use and to use a clear, coherent, sensitive narrative when responding that is, patient-practitioner narratives need to be aligned.

This line of argument corroborates findings of others. Two-way communication and good dialogue has been described as essential by people accessing physiotherapy for musculoskeletal pain, essential for collaborative rehabilitation, and possibly more important than specific treatment. ${ }^{58}$ Conversation analysis has been used to explore different interview styles used by physiotherapists in musculoskeletal assessment. Physiotherapists were typically found to follow their own agenda, however, when a more collaborative, shared conversation style was pursued, patients were allowed to describe their concerns more fully. ${ }^{59}$ Physiotherapists that engaged in postgraduate clinical conversation training demonstrated very positive feedback along with an increase in patient satisfaction in the service that those physiotherapists worked. ${ }^{60}$

Research has demonstrated that people experiencing pain report that they do not always feel listened to or believed by healthcare professionals (physiotherapists included). ${ }^{61}$ Training physiotherapists to actively encourage and facilitate conversations about pain may help to overcome some of these previously reported issues.

\section{Line of argument 2: train physiotherapists to be competent to} teach or coach people who are experiencing pain

The categories in this meta-ethnography demonstrate that people in pain have varied needs and need differing levels of information. The categories also reinforce that pain is often more complex than patients realise and that there is a lot to understand, comprehend and contextualise. In a biopsychosocial model this involves learning about pain sensitivity (bio), thoughts and emotions (psychological), context and lifestyle (social). Physiotherapists provide patients with a lot of information and may start myth busting individuals long standing beliefs about pain. Recognising that people learn in different ways and that context matters is important. People living with chronic pain may already have in-depth knowledge of their condition and seek support for reassurance or guidance to implement what they know. Others may be seeking more scientific explanations.

Physiotherapists commonly take on the role of educating patients to help people reconceptualise their pain using PNE with positive outcomes. ${ }^{2062}$ Research that investigates or explores coaching as part of physiotherapy intervention is heterogeneous and inconclusive in its findings, however, there are tentative findings that this is a positive approach. ${ }^{63}$ Physiotherapists require a range of skills; to be competent to teach, educate, coach and mentor. However, there is little information to inform how to develop physiotherapists to be competent to teach or coach people who are experiencing pain as part of pain education in preregistration physiotherapy training. This area of physiotherapy training requires more research.

\section{Line of argument 3: train physiotherapists to foster hope and self-efficacy in people who are experiencing pain}

The categories in this meta-ethnography demonstrate that people experiencing pain often seek hope from physiotherapists. Hope is an important concept and physiotherapists hold great power as health professionals, especially when viewed as experts. There is little research that has explored the concept of hope within pain management for physiotherapists. Soundy et al investigated hope in neurological physiotherapy as a concept beyond physical improvement. ${ }^{64}$ Physiotherapists reported that they were trained implicitly and explicitly to offer and manage hope because their profession is action orientated, focussing on helping people recover. ${ }^{64}$ How physiotherapists manage the concept of hope requires more investigation, though self-efficacy is a likely feature. Self-efficacy is defined as 'an individual's belief in his or her capacity to execute behaviours necessary to produce specific performance attainments ${ }^{9566}$ Self-efficacy reflects the ability to be able to control own motivation and behaviour. Many approaches in physiotherapy clinical practice encapsulate this including cognitive behavioural therapy, ${ }^{67}$ coaching, ${ }^{68}{ }^{69}$ psychologically informed physiotherapy ${ }^{70}$ and motivational interviewing. ${ }^{71}$

There is little evidence to demonstrate how these concepts can be incorporated in pre-registration training. It is not within the scope of the pre-registration curriculum to comprehensively cover these approaches, however, it is possible to 'break the teaching traditions' and lay the foundations of what these approaches have in common: to train physiotherapists to support patients in how they think and behave when experiencing pain. Understanding scope of practice, professional identify and boundaries is an important consideration.

\section{Strengths and limitations}

The strengths of meta-ethnography lie in its ability to undertake analytical evaluation of qualitative data. Beyond surface description, meta-ethnography allows conceptual understanding of the phenomena under investigation. This was particularly suited to this research where concepts evolving from patient experience were analysed to inform education. This may also be viewed as a limitation, as participants were not directly asked for their views on education. This meta-ethnography explored a broad range of patient experiences, to reflect 
routine physiotherapy clinical practice. This broad inclusion criteria may limit depth of analysis for particular participant groups.

\section{SUMMARY AND FUTURE RECOMMENDATIONS}

There have been significant advances in research and policy to inform pain education in preregistration physiotherapy in recent years, though there was a clear gap for the need to incorporate more patient views. Findings from this meta-ethnography elicit important concepts from patient experience to inform the development of future pain education in preregistration physiotherapy training. This patient needs-based approach aligns to many concepts of 'patient centredness' in physiotherapy. Future research is recommended to explore the acceptability and feasibility of implementing these findings in pain education in preregistration physiotherapy training.

\section{Twitter Kate Thompson @katethompson01}

Acknowledgements We thank Steven Williams (SW) for contributing to the study searching and screening process in his role as research intern.

Contributors KT, JM, MB and MIJ made a substantial contribution to each stage of this meta-ethnography. KT drafted the manuscript which JM, MB and MIJ subsequently contributed to, providing substantial input and approved the final version. KT acts as guarantor for the overall content and conduct of the work.

Funding This work was supported by a Health Education England (HEE) PhD studentship.

Competing interests None declared.

Patient consent for publication Not applicable.

Ethics approval This study does not involve human participants.

Provenance and peer review Not commissioned; externally peer reviewed.

Data availability statement All data relevant to the study are included in the article or uploaded as online supplemental information. Data relevant to the study is included and referenced within the manuscript.

Supplemental material This content has been supplied by the author(s). It has not been vetted by BMJ Publishing Group Limited (BMJ) and may not have been peer-reviewed. Any opinions or recommendations discussed are solely those of the author(s) and are not endorsed by BMJ. BMJ disclaims all liability and responsibility arising from any reliance placed on the content. Where the content includes any translated material, BMJ does not warrant the accuracy and reliability of the translations (including but not limited to local regulations, clinical guidelines, terminology, drug names and drug dosages), and is not responsible for any error and/or omissions arising from translation and adaptation or otherwise.

Open access This is an open access article distributed in accordance with the Creative Commons Attribution Non Commercial (CC BY-NC 4.0) license, which permits others to distribute, remix, adapt, build upon this work non-commercially, and license their derivative works on different terms, provided the original work is properly cited, appropriate credit is given, any changes made indicated, and the use is non-commercial. See: http://creativecommons.org/licenses/by-nc/4.0/.

\section{ORCID iDs}

Kate Thompson http://orcid.org/0000-0002-1999-6456

Mark I Johnson http://orcid.org/0000-0002-9421-9622

\section{REFERENCES}

1 Breivik H, Eisenberg E, O'Brien T, et al. The individual and societal burden of chronic pain in Europe: the case for strategic prioritisation and action to improve knowledge and availability of appropriate care. BMC Public Health 2013;13:1229-29.

2 Goldberg DS, McGee SJ. Pain as a global public health priority. BMC Public Health 2011;11:770.
3 Jackson T, Thomas S, Stabile V, et al. Prevalence of chronic pain in low-income and middle-income countries: a systematic review and meta-analysis. The Lancet 2015;385:S10.

4 Rice ASC, Smith BH, Blyth FM. Pain and the global burden of disease. Pain 2016;157:791-6.

5 Vos T, Barber RM, Bell B, et al. Global, regional, and national incidence, prevalence, and years lived with disability for 301 acute and chronic diseases and injuries in 188 countries, 1990-2013: a systematic analysis for the global burden of disease study 2013. Lancet 2015;386:743-800.

6 Fayaz A, Croft P, Langford RM, et al. Prevalence of chronic pain in the UK: a systematic review and meta-analysis of population studies. BMJ Open 2016;6:e010364.

7 Raja SN, Carr DB, Cohen M, et al. The revised international association for the study of pain definition of pain: concepts, challenges, and compromises. Pain 2020;161:1976-82.

8 Treede R-D, Rief W, Barke A, et al. A classification of chronic pain for ICD-11. Pain 2015;156:1003-7.

9 Thompson K, Johnson MI, Milligan J, et al. Twenty-Five years of pain education research-what have we learned? findings from a comprehensive scoping review of research into PREREGISTRATION pain education for health professionals. Pain 2018;159:2146-58.

10 Helme D. Trust me, I'm a patient: pain education for professionals from a lay perspective. Br J Pain 2012;6:79-80.

11 Tellier P-P, Bélanger E, Rodríguez C, et al. Improving undergraduate medical education about pain assessment and management: a qualitative descriptive study of stakeholders' perceptions. Pain Res Manag 2013;18:259-65.

12 Carr EC, Briggs EV, Briggs M, et al. Understanding factors that facilitate the inclusion of pain education in undergraduate curricula: perspectives from a UK survey. Br J Pain 2016;10:100-7.

13 Fishman SM, Young HM. Driving needed change in pain education. Pain Med 2016;17:1790-2.

14 Toye F, Seers K, Evans P. Including qualitative research in pain education: international association for the study of pain, 2018. Available: https://ebooks.iasp-pain.org/pain_education/

15 Synnott A, O'Keeffe M, Bunzli S, et al. Physiotherapists may stigmatise or feel unprepared to treat people with low back pain and psychosocial factors that influence recovery: a systematic review. $J$ Physiother 2015;61:68-76.

16 Gardner T, Refshauge K, Smith L, et al. Physiotherapists' beliefs and attitudes influence clinical practice in chronic low back pain: a systematic review of quantitative and qualitative studies. J Physiother 2017;63:132-43.

17 Wijma AJ, Crom-Ottens A, Knulst-Verlaan CM, et al. What is important in pain neuroscience education? the experience of patients with chronic pain. Physiotherapy 2015;101:e1628-9.

18 Robinson V, King R, Ryan CG, et al. A qualitative exploration of people's experiences of pain neurophysiological education for chronic pain: the importance of relevance for the individual. Man Ther 2016;22:56-61.

19 Robinson-Papp J, George MC, Dorfman D, et al. Barriers to chronic pain measurement: a qualitative study of patient perspectives. Pain Med 2015;16:1256-64.

20 King R, Robinson V, Elliott-Button $\mathrm{HL}$, et al. Pain Reconceptualisation after pain neurophysiology education in adults with chronic low back pain: a qualitative study. Pain Res Manag 2018;2018:3745651-51.

21 Morse JM. Using qualitative methods to access the pain experience. Br J Pain 2015;9:26-31.

22 Bearman M, Dawson P. Qualitative synthesis and systematic review in health professions education. Med Educ 2013;47:252-60.

23 Bunniss S, Kelly DR. Research paradigms in medical education research. Med Educ 2010;44:358-66.

24 Atkins S, Lewin S, Smith H, et al. Conducting a meta-ethnography of qualitative literature: lessons learnt. BMC Med Res Methodol 2008;8:21.

25 Barbour RS, Barbour M. Evaluating and synthesizing qualitative research: the need to develop a distinctive approach. J Eval Clin Pract 2003;9:179-86.

26 Mays N, Pope C, Popay J. Systematically reviewing qualitative and quantitative evidence to inform management and policy-making in the health field. J Health Serv Res Policy 2005;10 Suppl 1:6-20.

27 Kakos M, Fritzsche B. Meta-ethnography E\&E. Ethnography and Education 2017;12:129-33.

28 Noblit GW, Hare RD. Meta-ethnography: synthesizing qualitative studies. sage, 1988.

29 Toye F, Seers K, Allcock N, et al. A meta-ethnography of patients' experience of chronic non-malignant musculoskeletal pain. Osteoarthritis and Cartilage 2013;21:S259-60. 
30 Toye F, Seers K, Barker KL. Meta-ethnography to understand healthcare professionals' experience of treating adults with chronic non-malignant pain. BMJ Open 2017;7:e018411.

31 France EF, Cunningham M, Ring N, et al. Improving reporting of meta-ethnography: the eMERGe reporting guidance. BMC Med Res Methodol 2019;19:25.

32 CASP. Critical appraisal skills programme CASP qualitative checklist 2018.

33 QSR International Pty Ltd. NVivo (version 11) hwqcn-q-d-a-sh 2018.

34 Toye F, Seers K, Allcock N, et al. Meta-ethnography 25 years on: challenges and insights for synthesising a large number of qualitative studies. BMC Med Res Methodol 2014:14:80.

35 France EF, Uny I, Ring N, et al. A methodological systematic review of meta-ethnography conduct to articulate the complex analytical phases. BMC Med Res Methodol 2019;19:35.

36 Campbell R, Evans M, Tucker M, et al. Why don't patients do their exercises? Understanding non-compliance with physiotherapy in patients with osteoarthritis of the knee. J Epidemiol Community Health 2001;55:132-8.

37 Cooper K, Smith BH, Hancock E. Patient-centredness in physiotherapy from the perspective of the chronic low back pain patient. Physiotherapy 2008;94:244-52.

38 Cooper K, Smith BH, Hancock E. Patients' perceptions of selfmanagement of chronic low back pain: evidence for enhancing patient education and support. Physiotherapy 2009;95:43-50.

39 Dean SG, Smith JA, Payne S, et al. Managing time: an interpretative phenomenological analysis of patients' and physiotherapists' perceptions of adherence to therapeutic exercise for low back pain. Disabil Rehabil 2005;27:625-36.

40 Gustafsson M, Ekholm J, Ohman A. From shame to respect: musculoskeletal pain patients' experience of a rehabilitation programme, a qualitative study. J Rehabil Med 2004;36:97-103.

41 Liddle SD, Baxter GD, Gracey JH. Chronic low back pain: patients experiences, opinions and expectations for clinical management. Disabil Rehabil 2007;29:1899-909.

42 Mannerkorpi K, Gard G. Physiotherapy group treatment for patients with fibromyalgia--an embodied learning process. Disabil Rehabil 2003;25:1372-80.

43 Mårtensson L, Dahlin-Ivanoff S. Experiences of a primary health care rehabilitation programme. A focus group study of persons with chronic pain. Disabil Rehabil 2006;28:985-95.

44 May SJ. Patient satisfaction with management of back pain main. Physiotherapy 2001;87:4-20.

45 Medina-Mirapeix F, Escolar-Reina P, Gascón-Cánovas JJ, et al. Personal characteristics influencing patients' adherence to home exercise during chronic pain: a qualitative study. J Rehabil Med 2009;41:347-52.

46 Palazzo C, Klinger E, Dorner V, et al. Barriers to home-based exercise program adherence with chronic low back pain: patient expectations regarding new technologies. Ann Phys Rehabil Med 2016;59:107-13.

47 Sokunbi O, Cross V, Watt P, et al. Experiences of individuals with chronic low back pain during and after their participation in a spinal stabilisation exercise programme - a pilot qualitative study. Man Ther 2010;15:179-84.

48 Stenberg G, Fjellman-Wiklund A, Ahlgren C. "Getting confirmation": gender in expectations and experiences of healthcare for neck or back patients. J Rehabil Med 2012;44:163-71.

49 Stenberg G, Fjellman-Wiklund A, Ahlgren C. 'I am afraid to make the damage worse'--fear of engaging in physical activity among patients with neck or back pain--a gender perspective. Scand J Caring Sci 2014;28:146-54.

50 Toye F, Barker K. 'I can't see any reason for stopping doing anything, but I might have to do it differently'--restoring hope to patients with persistent non-specific low back pain--a qualitative study. Disabil Rehabil 2012;34:894-903.

51 Underwood MR, Harding G, Klaber Moffett J, et al. Patient perceptions of physical therapy within a trial for back pain treatments (UK BEAM) [ISRCTN32683578]. Rheumatology 2006;45:751-6.

52 Williamson E, Nichols V, Lamb SE. "If I can get over that, I can get over anything"--understanding how individuals with acute whiplash disorders form beliefs about pain and recovery: a qualitative study. Physiotherapy 2015;101:178-86.

53 Wilson S, Chaloner N, Osborn M, et al. Psychologically informed physiotherapy for chronic pain: patient experiences of treatment and therapeutic process. Physiotherapy 2017;103:98-105.

54 Available: https://www.iasp-pain.org/Education/CurriculaList.aspx? navltemNumber $=647$

55 EFIC. European pain Federation. Available: https://europeanpainfede ration.org/wp-content/uploads/2018/10/EFIC-Pain-PhysiotherapyCurriculum1.pdf

56 PPA Physiotherapy Framework - Entry Level Graduate to Expert - Describing the values, behaviours. Available: http://ppa.csp.org. uk/documents/ppa-physiotherapy-framework-entry-level-graduateexpert-describing-values-behaviours

57 Craig KD. The social communication model of pain. Canadian Psychology/Psychologie canadienne 2009;50:22-32.

58 Bernhardsson S, Samsson KS, Johansson K, Larsson MEH, et al. A preference for dialogue: exploring the influence of patient preferences on clinical decision making and treatment in primary care physiotherapy. Eur J Physiother 2019;21:107-14.

59 Cowell I, McGregor A, O'Sullivan P. How do physiotherapists solicit and explore patients' concerns in back pain consultations: a conversation analytic approach. Physiotherapy theory and practice 2019:1-17.

60 Ledbetter O, Davis C. Clinical conversations: assessing the impact of training on patient experience. Physiotherapy 2019;105:e60-1.

61 Toye F, Seers K, Allcock N. A meta-ethnography of patients experience of chronic non-malignant musculoskeletal pain. Southampton (UK, 2013.

62 Moseley GL, Butler DS. Fifteen years of explaining pain: the past, present, and future. J Pain 2015;16:807-13.

63 Rethorn ZD, Pettitt CD. What is the effect of health coaching delivered by physical therapists? A systematic review of randomized controlled trials. Phys Ther 2019;99:1354-70.

64 Soundy A, Smith B, Butler M, et al. A qualitative study in neurological physiotherapy and hope: beyond physical improvement. Physiother Theory Pract 2010;26:79-88.

65 Bandura A. The explanatory and predictive scope of self-efficacy theory. J Soc Clin Psychol 1986;4:359-73.

66 Bandura A. Self-Efficacy: toward a unifying theory of behavioral change. Psychol Rev 1977;84:191.

67 Morley S, Williams A, Hussain S. Estimating the clinical effectiveness of cognitive behavioural therapy in the clinic: evaluation of a CBT informed pain management programme. Pain 2008;137:670-80.

68 Iles R, Taylor NF, Davidson M, et al. Telephone coaching can increase activity levels for people with non-chronic low back pain: a randomised trial. J Physiother 2011;57:231-8.

69 Dufour SP, Graham S, Friesen J, et al. Physiotherapists supporting self-management through health coaching: a mixed methods program evaluation. Physiother Theory Pract 2015;31:29-38.

70 Denneny D. Frijdal Nee Klapper a, Bianchi-Berthouze N, et al. The application of psychologically informed practice: observations of experienced physiotherapists working with people with chronic pain. Physiotherapy 2019 (published Online First: 2019/04/02).

71 McGrane N, Galvin R, Cusack T, et al. Addition of motivational interventions to exercise and traditional physiotherapy: a review and meta-analysis. Physiotherapy 2015;101:1-12. 